\title{
Risk Factors for Inspiratory Muscle Weakness in Chronic Heart Failure
}

\author{
Naomi Kondo Nakagawa, Mariana Abreu Diz, Tatiana Satie Kawauchi, \\ Geisa Nascimento de Andrade, Iracema Ioco Kikuchi Umeda, Fernanda Murata Murakami, \\ Janaina Proença Oliveira-Maul, Juliana Araújo Nascimento, Newton Nunes, Júlio Yoshio Takada, \\ Antonio de Padua Mansur, and Lawrence Patrick Cahalin
}

\begin{abstract}
BACKGROUND: Chronic heart failure is commonly associated with inspiratory muscle weakness. However, few studies have investigated the risk factors for inspiratory muscle weakness in individuals with chronic heart failure and systolic dysfunction (left-ventricular ejection fraction [LVEF] < 40\%). METHODS: Seventy subjects were recruited in a cardiac center. We assessed clinical parameters, smoking history, peripheral muscle strength, pulmonary function, echocardiographic variables, and brain natriuretic peptide. The subjects were classified with inspiratory muscle weakness when the maximum inspiratory pressure was $<70 \%$ of predicted values. RESULTS: Thirty-six subjects (51\%) had inspiratory muscle weakness. The subjects with inspiratory muscle weakness and the subjects with no inspiratory muscle weakness were similar in age, sex, body mass index, medication use, and physical activity. However, the subjects with inspiratory muscle weakness had lower LVEF $(P=.003)$, systolic blood pressure $(P=.01)$, diastolic blood pressure $(P=.042)$, quadriceps muscle strength $(P=.02)$, lung function $(P=.035)$, increased brain natriuretic peptide $(P=.02)$, smoking history $(P=.01)$, and pulmonary hypertension incidence $(P=.03)$. Multivariate logistic regression analysis found a lower LVEF, increased smoking history, and lower systolic blood pressure as significant independent predictors for inspiratory muscle weakness. CONCLUSIONS: The combination of lower LVEF, lower systolic blood pressure, and smoking history predicted inspiratory muscle weakness. Patients with suspected inspiratory muscle weakness should be examined and, if inspiratory muscle weakness exists, then inspiratory muscle training should be provided. Reducing inspiratory muscle weakness has the potential to improve many of the deleterious effects of chronic heart failure. Key words: cardiovascular diseases; respiratory function tests; respiratory structure and function; tobacco. [Respir Care 2020;65(4):507-516.

(C) 2020 Daedalus Enterprises]
\end{abstract}

\section{Introduction}

Individuals with chronic heart failure have dyspnea and fatigue, skeletal muscle weakness, and exercise intoler- ance. One key group of skeletal muscles that have been found to be related to dyspnea and fatigue as well as exercise tolerance of patients with chronic heart failure are the inspiratory muscles. ${ }^{1}$ Inspiratory muscle weakness is associated with greater dyspnea and fatigue, and with poorer

\footnotetext{
with the Department of Physical Therapy, University of Miami Miller School of Medicine, Miami, Florida.

The present study was sponsored by Fundação de Amparo à Pesquisa do Estado de São Paulo (FAPESP 2013/13598-1). The funder had no role in the study design, data collection, data analysis, data interpretation, decision to publish, or preparation of the manuscript.
} 
exercise capacity and survival. ${ }^{2}$ In view of the above, inspiratory muscle weakness is an important factor in determining the prognosis and therapeutic options available for subjects with chronic heart failure. ${ }^{3}$

It has been accepted that inspiratory muscle weakness is present when the observed maximum inspiratory pressure $\left(\mathrm{P}_{\text {Imax }}\right)$ is $<70 \%$ of the predicted value. ${ }^{4}$ A relatively large percentage of subjects with chronic heart failure were observed to have inspiratory muscle weakness (30-50\%), with an even greater percentage of older subjects with chronic heart failure experiencing inspiratory muscle weakness $(70 \%)$. In fact, $76 \%$ of older subjects with chronic heart failure who were admitted for a chronic heart failure exacerbation were observed to have inspiratory muscle weakness that persisted in $71 \%$ of the subjects at the time of discharge. ${ }^{5}$ Thus, inspiratory muscle weakness is common in chronic heart failure, and a better understanding of the mechanisms responsible for it is needed because it represents a poorer clinical condition. ${ }^{6}$

Several proposed mechanisms for inspiratory muscle weakness include reduced cardiac output; increased proteolysis, with loss of muscle mass and atrophy; ${ }^{7}$ and oxidative stress, which induces protein modifications; and contractile dysfunction. ${ }^{8}$ Although the above mechanisms have been proposed, to the best of our knowledge, there has been no comprehensive examination of clinical characteristics responsible for inspiratory muscle weakness in subjects with chronic heart failure. Therefore, we prospectively examined a variety of clinical characteristics, the functional capacity, and the systemic inflammatory and/or cardiovascular disease markers in subjects with chronic heart failure (New York Heart Association functional class II and III) to help identify risk factors for inspiratory muscle weakness.

\section{Methods}

\section{Study Design and Study Population}

This cross-sectional study complied with the Declaration of Helsinki and was approved by the ethics committee of the Faculdade de Medicina da Universidade de São Paulo (ID 232/12). Subjects were consecutively recruited at a heart institute from September 2012 to May 2016, and

The authors have disclosed no conflicts of interest.

Correspondence: Naomi Kondo Nakagawa PhD, Faculdade de Medicina da Universidade de Sao Paulo, Av. Dr Arnaldo, 455, room 1150. São Paulo, SP 01246-930, Brazil. E-mail: naomi.kondo@ fm.usp.br.

DOI: $10.4187 /$ respcare.06766

\section{QUICK LOOK}

\section{Current knowledge}

Chronic heart failure is commonly associated with inspiratory muscle weakness. The inspiratory muscle weakness is associated with greater dyspnea and fatigue, poorer survival, and poorer exercise capacity. Inspiratory muscle weakness has been accepted as an important factor in determining the prognosis for patients with chronic heart failure.

\section{What this paper contributes to our knowledge}

This study provided valuable findings to assist in the clinical decision-making and management of patients with chronic heart failure. The combination of a lower left-ventricular ejection fraction, lower systolic blood pressure, and smoking history can predict inspiratory muscle weakness. In patients with chronic chronic heart failure, inspiratory muscle training may represent a key strategy in their treatment.

were entered into the study after giving written informed consent to participate. The inclusion criteria were the following: both sexes, left-ventricular ejection fraction (LVEF) $<40 \%$, New York Heart Association functional class II or III, with optimized drug therapy, and clinically stable. The exclusion criteria were the following: myocardial infarction in the past 6 months; uncontrolled and/or severe arrhythmia; pleural effusion or pulmonary congestion; $\mathrm{S}_{\mathrm{pO}_{2}}$ at rest of $<92 \%$; respiratory infection in the past $30 \mathrm{~d}$; and cognitive, neurologic, or orthopedic alterations that could affect the performance during muscle strength or functional capacity assessments..$^{9,10}$

\section{Assessments}

Clinical history, physical examination, and functional capacity tests were performed. LVEF was calculated from apical images according to the Simpson method by using echo-Doppler cardiography. Pulmonary hypertension was defined by echocardiography estimation from the velocity of tricuspid regurgitation. Physical activity was investigated by using the long form of the International Physical Activity Questionnaire. ${ }^{11}$ Health-related quality of life was also assessed by using the Short-Form 36 Questionnaire and the Minnesota Living with Heart Failure Questionnaire. ${ }^{12,13}$ Blood samples were obtained for inflammatory and cardiovascular diseases biomarkers determination by using Luminex analysis (Milliplex Map Human cytokine/chemokine and cardiovascular assays kits, Merck Millipore, Burlington, Massachusetts), in- 
cluding B-type natriuretic peptide analysis (brain natriuretic peptide immunoassay, Biosite Diagnostics, San Diego, California).

Respiratory muscle strength was measured for $\mathrm{P}_{\mathrm{Imax}}$ and maximum expiratory pressure $\left(\mathrm{P}_{\mathrm{Emax}}\right)$ by using a mouth pressure transducer (MVD-300 Microhard System, GlobalMed, Porto Alegre, Brazil). According to the American Thoracic Society guidelines, ${ }^{14}$ we standardized measurements of $\mathrm{P}_{\text {Imax }}$ close to functional residual capacity and $\mathrm{P}_{\text {Emax }}$ close to total lung capacity. Both were measured 3 consecutive times, and the highest absolute value was registered. ${ }^{14}$ The results were presented as the percentage of predicted $\mathrm{P}_{\text {Imax }}$ and $\mathrm{P}_{\mathrm{Emax}}$ by taking into account the specific population of the country. ${ }^{15}$ Spirometry for lung function determination (Koko Legend, InSpire Health, Longmont, Colorado) was performed according to the American Thoracic Society guidelines. ${ }^{16}$ Classification of type and severity of lung disease was performed according to the Global Initiative for Chronic Obstructive Lung Disease guideline (2010). ${ }^{17}$ Briefly, (A) restrictive alterations were: $\mathrm{FVC}<80 \%$ predicted and $\mathrm{FEV}_{1} / \mathrm{FVC} \geq 0.7$ with $\mathrm{FEV}_{1}>80 \%$ of predicted values; (B) obstructive alterations were: $\mathrm{FEV}_{1}<80 \%$ predicted and $\mathrm{FEV}_{1} / \mathrm{FVC}<0.7$; (C) mixed alterations were: FVC $<80 \%$ and $\mathrm{FEV}_{1}<80 \%$ predicted and $\mathrm{FEV}_{1} / \mathrm{FVC}<0.7$.

Handgrip and quadriceps muscle strength were also assessed, by using dynamometers (Jamar [Sammons Preston Rolyan Inc, Bolingbrook, Illinois], and MicroFet2 [Hoggan Health, Utah], respectively). The subjects sat in a chair, with the hips and back in $90^{\circ}$ of flexion, sufficient to maximally extend the knee ${ }^{6}$ for quadriceps force analysis in both limbs, and with $90^{\circ}$ of elbow flexion and $0^{\circ}$ hand extension for hand grip force analysis in both limbs. The results are presented as the average newtons of 3 maximum tests. The 6-min walk test was performed according to the American Thoracic Society Standards. ${ }^{18}$

\section{Statistical Analysis}

Statistical analysis was performed with standard software (Statistical Analysis System, SAS version 9.3, SAS Institute, Cary, North Carolina). The 2 groups of the study were defined according to the presence of inspiratory muscle weakness or no inspiratory muscle weakness. The presence of inspiratory muscle weakness was defined by $\mathrm{P}_{\text {Imax }}<70 \%$ of the predicted value. ${ }^{4}$ Results of categorical variables were expressed as absolute numbers and percentages, and comparisons were performed by using the chi-square test. Continuous variables were expressed as mean \pm SD or median $(25 \%-75 \%)$ when appropriate, and comparisons were performed by using the unpaired $t$ test or the Mann-Whitney test.

To detect associations between variables, we used the Pearson or the Spearman correlation coefficient, as appro- priate, based on the distribution of the data. To determine predictors for inspiratory muscle weakness, we performed multivariate logistic regression analysis (stepwise method) by using, as a dependent variable, the dichotomous classification for inspiratory muscle weak: 1 as $<70 \%$ of predicted values) and normal was shown as 0 . The other variables: body mass index, LVEF, systolic blood pressure (SBP), pack-years, brain natriuretic peptide, predicted $\mathrm{FEV}_{1}$ and predicted $\mathrm{FVC}$. We calculated the probability of inspiratory muscle weakness as previously described. ${ }^{19}$ The receiver operating characteristic curve analysis was used to determine the accuracy for inspiratory muscle weakness classification. A level of $P<.05$ was considered statistically significant.

\section{Results}

Seventy subjects who were clinically stable entered the study. Thirty-six subjects (51\%) had inspiratory muscle weakness. The inspiratory muscle weakness and the no inspiratory muscle weakness groups had a similar number of subjects with sinus rhythm ( $47 \%$ vs $68 \%$, respectively), atrial fibrillation ( $30 \%$ vs $12 \%$, respectively), and implantable cardioverter-defibrillator ( $22 \%$ vs $29 \%$, respectively) $(P=.12)$.

Demographic and clinical characteristics are presented in Table 1 . The inspiratory muscle weakness and the no inspiratory muscle weakness groups had similar age, sex, body mass index, New York Heart Association functional class, etiology of chronic heart failure, physical activity level, use of medications, and comorbidities, with the exception of the proportion of subjects with pulmonary hypertension that was greater in the inspiratory muscle weakness group compared with the no inspiratory muscle weakness group $(P=.03)$. There was a weak significant correlation between inspiratory muscle weakness and pulmonary hypertension $(\mathrm{r}=-0.26$ and $P=.03)$.

LVEF was lower in the inspiratory muscle weakness group compared with the no inspiratory muscle weakness group $(P=.003)$, and the inspiratory muscle weakness group had greater mean left-ventricular end systolic volume (211 vs $129 \mathrm{~mL}$, respectively; $P=.02$ ) and diastole (254 vs $212 \mathrm{~mL}$, respectively; $P=.01$ ) compared with the no inspiratory muscle weakness group. The proportions of never smokers, ex-smokers, and current smokers between the 2 groups were similar. However, when taking into account smoking history, the inspiratory muscle weakness and the no inspiratory muscle weakness groups differed in the mean pack-years $(P=.01)$, and in the mean number of cigarettes per day $(P=.043)$.

In addition, the univariate analysis (Table 2 ) result was that subjects with inspiratory muscle weakness had lower systolic and diastolic blood pressures $(P=.005$ and 
Table 1. Demographic and Clinical Characteristics of the 70 Subjects With Chronic Heart Failure

\begin{tabular}{|c|c|c|c|c|}
\hline Characteristic & $\begin{array}{l}\text { All Subjects } \\
\quad(N=70)\end{array}$ & $\begin{array}{l}\text { Inspiratory Muscle Weakness } \\
\qquad(n=36)\end{array}$ & $\begin{array}{l}\text { No Inspiratory Muscle Weakness } \\
\qquad(n=34)\end{array}$ & $P$ \\
\hline Age, mean \pm SD y & $56 \pm 9$ & $56 \pm 10$ & $56 \pm 8$ & .90 \\
\hline Males, $n(\%)$ & $46(66)$ & $27(75)$ & $19(56)$ & .09 \\
\hline Body mass index, mean $\pm \mathrm{SD} \mathrm{kg} / \mathrm{m}^{2}$ & $27.5 \pm 5.1$ & $26.6 \pm 4.5$ & $28.6 \pm 5.6$ & .11 \\
\hline Left-ventricular ejection fraction, mean $\pm \mathrm{SD} \%$ & $28.7 \pm 6.2$ & $26.8 \pm 5.7$ & $31.1 \pm 5.8$ & .003 \\
\hline NYHA functional class III, $n(\%)$ & $39(56)$ & $22(61)$ & $17(50)$ & .35 \\
\hline Dilated cardiomyopathy, $n(\%)$ & $32(46)$ & $20(56)$ & $12(35)$ & .09 \\
\hline Chagas cardiomyopathy, $n(\%)$ & $13(19)$ & $7(19)$ & $6(18)$ & .84 \\
\hline Ischemic cardiomyopathy, $n(\%)$ & $25(36)$ & $9(25)$ & $16(47)$ & .054 \\
\hline Myocardial infarction, $n(\%)$ & $28(40)$ & $13(36)$ & $15(44)$ & .49 \\
\hline Hypertension, $n(\%)$ & $52(74)$ & $26(72)$ & $26(76)$ & .68 \\
\hline Dyslipidemia, $n(\%)$ & $40(57)$ & $21(58)$ & $19(56)$ & .84 \\
\hline Diabetes, $n(\%)$ & $22(31)$ & $12(33)$ & $10(29)$ & .72 \\
\hline Pulmonary hypertension, $n(\%)$ & $32(46)$ & $21(58)$ & $11(34)$ & .03 \\
\hline \multicolumn{5}{|l|}{ Smoking status, $n(\%)$} \\
\hline Never smokers & $28(40)$ & $13(36)$ & $15(44)$ & .49 \\
\hline Ex-smokers & $39(56)$ & $21(58)$ & $18(53)$ & .65 \\
\hline Current smokers & $3(4)$ & $2(5)$ & $1(3)$ & .59 \\
\hline No. pack-years, mean & 17.6 & 24.7 & 10.1 & .01 \\
\hline No. cigarettes/d, mean & 13.0 & 16.5 & 8.9 & .043 \\
\hline \multicolumn{5}{|l|}{ Physical activity, $n(\%)$} \\
\hline Very active & $2(3)$ & $1(3)$ & $1(3)$ & .30 \\
\hline Active & $28(40)$ & $15(41)$ & $13(38)$ & .81 \\
\hline Irregularly active & $25(36)$ & $10(28)$ & $15(44)$ & .14 \\
\hline Sedentary & $15(21)$ & $10(28)$ & $5(15)$ & .11 \\
\hline \multicolumn{5}{|l|}{ Medications, $n(\%)$} \\
\hline Amiodarone & $25(36)$ & $9(25)$ & $14(41)$ & .15 \\
\hline Anticoagulants & $10(14)$ & $7(19)$ & $3(9)$ & .20 \\
\hline Angiotensin-converting enzyme inhibitors & $42(60)$ & $22(61)$ & $20(59)$ & .85 \\
\hline Antiplatelets & $45(64)$ & $24(67)$ & $21(62)$ & .67 \\
\hline$\beta$-blockers & $69(99)$ & $35(97)$ & $34(100)$ & .33 \\
\hline Digoxin & $20(29)$ & $9(25)$ & $11(32)$ & .49 \\
\hline Diuretics & $66(94)$ & $34(94)$ & $32(94)$ & .95 \\
\hline
\end{tabular}

Univariate analysis by using the $t$ test or Mann-Whitney test for continuous variables, or the chi-square test for categorical variables.

NYHA $=$ New York Heart Association

$P=.042$, respectively), lower $\mathrm{P}_{\text {Emax }}(P=.02)$, lower nondominant quadriceps muscle strength $(P=.02)$, and impaired lung function $(P=.035)$. However, when using the Global Initiative for Chronic Obstructive Lung Disease $^{17}$ classification for diagnosis and staging of lung disease, there were no significant differences $(P=.17)$ between the inspiratory muscle weakness and the no inspiratory muscle weakness groups in the number of subjects with normal lung function (8 vs 11 subjects, respectively), obstructive lung function (7 vs 11 subjects, respectively), restrictive lung function (19 vs 9 subjects, respectively), and mixed pulmonary alterations (2 vs 3 subjects, respectively).

No significant differences were found between the 2 groups with regard to health-related quality of life when using the Short-Form 36 Questionnaire and the Minnesota
Living with Heart Failure Questionnaire. There were no significant differences in systemic inflammatory and cardiovascular biomarkers between the inspiratory muscle weakness and the no inspiratory muscle weakness groups (Table 3). However, brain natriuretic peptide concentrations were significantly higher in the inspiratory muscle weakness group compared with the no inspiratory muscle weakness group $(P=.02)$.

Stepwise multivariate logistic regression analysis identified several independent risk factors for inspiratory muscle weakness (Table 4). The combination of 3 significant predictors (LVEF + pack-years + SBP) showed the area under the curve of 0.79 (Fig. 1), and we calculated the likelihood of inspiratory muscle weakness, as published by Pavlou et al, ${ }^{19}$ by using beta estimates of logistic regression: 
Table 2. Lung Function, Respiratory and Peripheral Muscle Strength, Functional Capacity, and Health-Related Quality of Life Data of the 70 Subjects With Chronic Heart Failure

\begin{tabular}{|c|c|c|c|c|}
\hline Parameter & $\begin{array}{l}\text { All Subjects } \\
(N=70)\end{array}$ & $\begin{array}{c}\text { Inspiratory Muscle } \\
\text { Weakness Group } \\
(n=36)\end{array}$ & $\begin{array}{c}\text { No Inspiratory Muscle } \\
\text { Weakness Group } \\
(n=34)\end{array}$ & $P$ \\
\hline \multicolumn{5}{|l|}{ Vital signs } \\
\hline Systolic blood pressure, $\mathrm{mm} \mathrm{Hg}$ & $117.4 \pm 24.0$ & $109.7 \pm 21.3$ & $125.5 \pm 24.4$ & .005 \\
\hline Diastolic blood pressure, $\mathrm{mm} \mathrm{Hg}$ & $71.3 \pm 13.8$ & $68.1 \pm 12.4$ & $74.8 \pm 14.6$ & .042 \\
\hline Heart rate, beats/min & $65 \pm 9$ & $64 \pm 9$ & $66 \pm 9$ & .32 \\
\hline \multicolumn{5}{|l|}{ Respiratory muscle strength, $\mathrm{cm} \mathrm{H}_{2} \mathrm{O}$} \\
\hline Maximum inspiratory pressure & $71.1 \pm 24.9$ & $55.1 \pm 17.4$ & $88.0 \pm 20.1$ & $<.001$ \\
\hline Maximum expiratory pressure & $88.3 \pm 35.0$ & $78.8 \pm 33.6$ & $98.5 \pm 33.9$ & .02 \\
\hline \multicolumn{5}{|l|}{ Peripheral muscle strength, $\mathrm{N}$} \\
\hline Dominant hand grip & $69.1 \pm 21.2$ & $65.8 \pm 19.9$ & $72.5 \pm 22.4$ & .19 \\
\hline Nondominant hand grip & $64.7 \pm 20.6$ & $62.9 \pm 16.9$ & $66.2 \pm 23.6$ & .53 \\
\hline Dominant quadriceps & $238.6 \pm 76.2$ & $226.1 \pm 68.3$ & $252.4 \pm 83.0$ & .16 \\
\hline Nondominant quadriceps & $236.8 \pm 88.9$ & $210.7 \pm 76.7$ & $261.2 \pm 93.7$ & .02 \\
\hline \multicolumn{5}{|l|}{ Functional capacity } \\
\hline 6-min walk distance, $\mathrm{m}$ & $430.6 \pm 88.1$ & $420.2 \pm 65.5$ & $441.6 \pm 107.0$ & .32 \\
\hline \multicolumn{5}{|l|}{ Lung function. $\%$} \\
\hline Predicted FVC & $76.5 \pm 14.8$ & $71.8 \pm 14.8$ & $81.4 \pm 13.3$ & .006 \\
\hline Predicted $\mathrm{FEV}_{1}$ & $70.6 \pm 16.9$ & $66.1 \pm 17.4$ & $75.4 \pm 15.2$ & .02 \\
\hline Forced inspiratory flow $25 \%-75 \%$ & $64.3 \pm 24.5$ & $58.3 \pm 23.1$ & $70.7 \pm 24.7$ & .035 \\
\hline $\mathrm{FEV}_{1} / \mathrm{FVC}$ & $0.73 \pm 0.09$ & $0.73 \pm 0.10$ & $0.73 \pm 0.07$ & .79 \\
\hline \multicolumn{5}{|l|}{ Health-related quality of life } \\
\hline Short Form-36 Questionnaire Physical domain & $34 \pm 9$ & $33 \pm 9$ & $34 \pm 10$ & .51 \\
\hline Short Form-36 Questionnaire Mental domain & $47 \pm 12$ & $45 \pm 13$ & $50 \pm 11$ & .16 \\
\hline Minnesota Living with Heart Failure Questionnaire & $41 \pm 23$ & $44 \pm 22$ & $39 \pm 25$ & .36 \\
\hline
\end{tabular}

$\overline{\text { Data are presented as }}$ mean $\pm \mathrm{SD}$; univariate analysis by using the $t$ test or Mann-Whitney test.

1. Risk coefficient $(\mathrm{RC})=6.0694+(0.0315 \times$ packyears $)-(0.1038 \times$ LVEF $)-(0.03 \times \mathrm{SBP})$ and

2. Probability of inspiratory muscle weakness $=($ Exponential $[\mathrm{RC}]) /(1+$ Exponential $[\mathrm{RC}])$

\section{Discussion}

We investigated demographic and clinical characteristics as well as systemic inflammatory and/or cardiovascular disease biomarkers to identify predictors of inspiratory muscle weakness in subjects with systolic chronic heart failure. Higher LVEF and SBP increase the likelihood of normal inspiratory muscle strength, whereas increased smoking history (pack-years), and lower LVEF and SBP increased the likelihood of inspiratory muscle weakness. We determined a model of inspiratory muscle weakness prediction (area under the curve of 0.79) based on simple, noninvasive, and easy-to-obtain variables (LVEF, SBP, and pack-years). In this study, $51 \%$ of the subjects with chronic heart failure had inspiratory muscle weakness, which was in keeping with earlier reports. ${ }^{5,20,21}$ Besides a marked reduction in the percentage of predicted $\mathrm{P}_{\text {Imax }}$, the inspiratory muscle weakness group also showed a compa- rably reduced percentage of predicted $\mathrm{P}_{\text {Emax }}$, which has not been previously reported.

Skeletal muscle performance depends on several key factors, including perfusion, mass, composition, and energy metabolism among other factors. ${ }^{22}$ Among the many clinical parameters we examined, lower LVEF and blood pressure explained part of the mechanisms responsible for inspiratory muscle weakness. Systolic dysfunction reduces cardiac output and increases end-systolic and diastolic left ventricular volume, which results in increased pulmonary vascular pressure and congestion, and subsequent pulmonary hypertension. The reduction in SBP is likely to compromise respiratory muscle blood flow and perfusion because of a reduction in cardiac output. ${ }^{23-25}$ Increasing cardiac output has the potential to improve SBP, to decrease a ventilation-perfusion mismatch, and to improve respiratory muscle strength.

A reduction in type I skeletal muscle fibers contributes to poorer oxygen extraction and consumption that also limits skeletal muscle function and performance. ${ }^{26}$ In our study, peripheral limb muscle strength was less affected than the respiratory muscles. It seems that systolic dysfunction may have a preferential selective effect on the 
Table 3. Results of Cardiovascular Disease and Inflammatory Biomarkers in 70 Subjects With Chronic Heart Failure

\begin{tabular}{|c|c|c|c|c|}
\hline Analytes & $\begin{array}{l}\text { All Subjects } \\
\quad(N=70)\end{array}$ & $\begin{array}{l}\text { Inspiratory Muscle Weakness } \\
\qquad(n=36)\end{array}$ & $\begin{array}{l}\text { No Inspiratory Muscle Weakness } \\
\qquad(n=34)\end{array}$ & $P$ \\
\hline BNP, pg/mL & $157.5(51.5-413.45)$ & $256.0(95.3-594.4)$ & $109.9(46.4-220.1)$ & .02 \\
\hline Lactate, $\mathrm{mmol} / \mathrm{L}$ & $2.5(1.8-3.1)$ & $2.5(1.8-3.3)$ & $2.4(1.8-3.1)$ & .79 \\
\hline GOT, ng/mL & $26(21-34)$ & $28(23-36)$ & $24(19-26)$ & .69 \\
\hline GPT, ng/mL & $30(24-40)$ & $35(27-44)$ & $28(23-38)$ & .66 \\
\hline ADAMST-13, ng/mL & 747 (296-1753) & $661(235-1791)$ & $771(360-1607)$ & .47 \\
\hline GDF-15, ng/mL & $1.4(0.3-2.6)$ & $2(0.2-2.9)$ & $1.1(0.4-1.8)$ & .64 \\
\hline Myoglobin, ng/mL & $62.25(13.1-107)$ & $64.3(12.7-92.9)$ & $50.6(19.2-160.0)$ & .57 \\
\hline sICAM-1, ng/mL & $122.7(17.9-233.1)$ & $142.8(10.5-251.0)$ & $112.5(18.6-185.1)$ & .09 \\
\hline $\mathrm{MPO}, \mathrm{ng} / \mathrm{mL}$ & 368 (88-954) & $356(134-1334)$ & $388(75-943)$ & .16 \\
\hline P-selectin, ng/mL & $77.6(17.6-175.4)$ & $96.6(23.4-185.1)$ & $73.9(14.6-154.0)$ & .82 \\
\hline NGAL, ng/mL & $130.0(48.2-326.4)$ & $131.4(62.9-319.3)$ & $128.6(40.7-333.5)$ & .29 \\
\hline $\mathrm{sVCAM}-1, \mathrm{ng} / \mathrm{mL}$ & 609 (198-929) & 798 (179-1035) & $529(279-701)$ & .17 \\
\hline EGF, ng/mL & $67.1(26.4-122)$ & $62.1(31.4-112.3)$ & $72.1(21.4-174.4)$ & .65 \\
\hline Eotaxin, ng/mL & $124.0(56.6-181.2)$ & $124.0(59.2-174.4)$ & $124.2(51.5-209.0)$ & .58 \\
\hline TGF- $\alpha, p g / d L$ & $3.4(2.1-7.6)$ & $4.0(2.5-7.7)$ & $3.0(1.3-7.5)$ & .27 \\
\hline GM-CSF, pg/dL & $1.6(0.8-2.6)$ & $1.5(1.1-2.6)$ & $1.7(0.7-2.4)$ & .29 \\
\hline IFN- $\alpha 2, \mathrm{pg} / \mathrm{dL}$ & $4.0(1.8-6.1)$ & $4.2(2.3-6.3)$ & $3.5(0.5-5.9)$ & .27 \\
\hline IFN- $\gamma, \mathrm{pg} / \mathrm{dL}$ & $2.1(1.4-3.6)$ & $2.6(1.7-3.9)$ & $1.7(1.2-3.2)$ & .59 \\
\hline $\mathrm{IL}-10, \mathrm{pg} / \mathrm{dL}$ & $0.4(0.3-0.7)$ & $0.7(0.4-0.9)$ & $0.3(0.2-0.5)$ & .17 \\
\hline $\mathrm{IL}-17, \mathrm{pg} / \mathrm{dL}$ & $1.5(1.1-3.3)$ & $2.1(1.3-5.8)$ & $1.4(0.9-2.5)$ & .32 \\
\hline $\mathrm{IL}-1 \beta, \mathrm{pg} / \mathrm{dL}$ & $0.9(0.7-1.3)$ & $0.9(0.7-1.5)$ & $1.0(0.6-1.2)$ & .29 \\
\hline $\mathrm{IL}-2, \mathrm{pg} / \mathrm{dL}$ & $1.0(0.9-1.2)$ & $1.1(0.9-1.3)$ & $1.0(0.6-1.2)$ & .28 \\
\hline $\mathrm{IL}-3, \mathrm{pg} / \mathrm{dL}$ & $0.4(0.2-0.8)$ & $0.4(0.3-0.6)$ & $0.3(0.1-0.9)$ & .96 \\
\hline $\mathrm{IL}-4, \mathrm{pg} / \mathrm{dL}$ & $92.6(25.4-164.9)$ & $100.3(19.1-139.1)$ & $88.5(31.6-192.9)$ & .14 \\
\hline $\mathrm{IL}-5, \mathrm{pg} / \mathrm{dL}$ & $0.8(0.6-1.1)$ & $0.9(0.6-1.5)$ & $0.8(0.5-1.0)$ & .29 \\
\hline $\mathrm{IL}-6, \mathrm{pg} / \mathrm{dL}$ & $1(0.5-2.3)$ & $1.2(0.7-2.5)$ & $0.7(0.5-2.0)$ & .25 \\
\hline $\mathrm{IL}-8, \mathrm{pg} / \mathrm{dL}$ & $7.9(3.6-16.4)$ & $11.2(7.5-18.6)$ & $5.5(2.8-8.2)$ & .40 \\
\hline $\mathrm{P}_{\operatorname{Imax}}-1 \alpha, \mathrm{pg} / \mathrm{dL}$ & $8.2(4.8-9.7)$ & $8.2(5-10.1)$ & $8.2(4.8-9.3)$ & .34 \\
\hline $\mathrm{P}_{\text {Imax }}-1 \beta, \mathrm{pg} / \mathrm{dL}$ & $24.7(17.3-41.1)$ & $26(18.8-39.6)$ & $22.3(16.4-44.5)$ & .33 \\
\hline $\mathrm{TNF}-\alpha, \mathrm{pg} / \mathrm{dL}$ & $9.8(7.2-12.4)$ & $10(7.8-14.0)$ & $9.6(6.0-12.2)$ & .28 \\
\hline $\mathrm{TNF}-\beta, \mathrm{pg} / \mathrm{dL}$ & $0.1(0.1-0.5)$ & $0.1(0.1-1.1)$ & $0.1(0.1-0.2)$ & .27 \\
\hline VEGF, ng/mL & $67(46.3-133.6)$ & $78.8(50.8-161.8)$ & $60(46.3-84.6)$ & .67 \\
\hline
\end{tabular}

Data are presented as median (range, 25-75\% quartiles); univariate analysis by using the $t$ test or the Mann-Whitney test. $\mathrm{BNP}=$ brain natriuretic peptide

$\mathrm{GOT}=$ glutamic-oxaloacetate transaminase

GPT $=$ glutamic-pyruvic transaminase

ADAMST $-13=$ von Willebrand factor-cleaving protease 13

GDF-15 = growth differentiation factor-15

sICAM-1 = soluble intercellular adhesion molecule-1

$\mathrm{MPO}=$ myeloperoxidase

NGAL $=$ serum neutrophil gelatinase-associated lipocalin

sVCAM-1 = soluble vascular cell adhesion molecule-1

$\mathrm{EGF}=$ epidermal growth factor

$\mathrm{TGF}=$ transforming growth factor

GM-CSF $=$ granulocyte-macrophage colony-stimulating factor

IFN $=$ interferon

$\mathrm{IL}=$ interleukin

$\mathrm{P}_{\text {Imax }}=$ maximum inspiratory pressure

$\mathrm{TNF}=$ tumor necrosis factor

VEGF $=$ vascular endothelial growth factor

skeletal muscles of the body with a primary negative effect on the respiratory muscles, followed by the lower limb muscles. This type of compartmentalization of muscle dysfunction in the diaphragm and lower limbs accompanied by preserved upper limb muscle function has been reported in subjects with COPD. ${ }^{27}$
In the subjects with chronic heart failure, results of study point out that an oxygen demand-delivery mismatch in the respiratory muscles may lead to a reduction in the perfusion reflex of the peripheral limb muscles, which features a respiratory metaboreflex. ${ }^{25}$ In the present study, quadriceps muscle strength was reduced in the nondominant limb 
Table 4. Results of Logistic Regression Analysis to Determine Risk Factors for Inspiratory Muscle Weakness

\begin{tabular}{lcc}
\hline \hline \multicolumn{1}{c}{ Parameter } & $\begin{array}{l}\text { Odds } \\
\text { Ratio }\end{array}$ & Wald 95\% CI \\
\hline $\begin{array}{l}\text { Left-ventricular ejection } \\
\text { fraction }\end{array}$ & 0.90 & $0.81,0.99$ \\
$\begin{array}{l}\text { Pack-years } \\
\text { Systolic blood pressure }\end{array}$ & 1.03 & $1.01,1.06$ \\
\hline
\end{tabular}

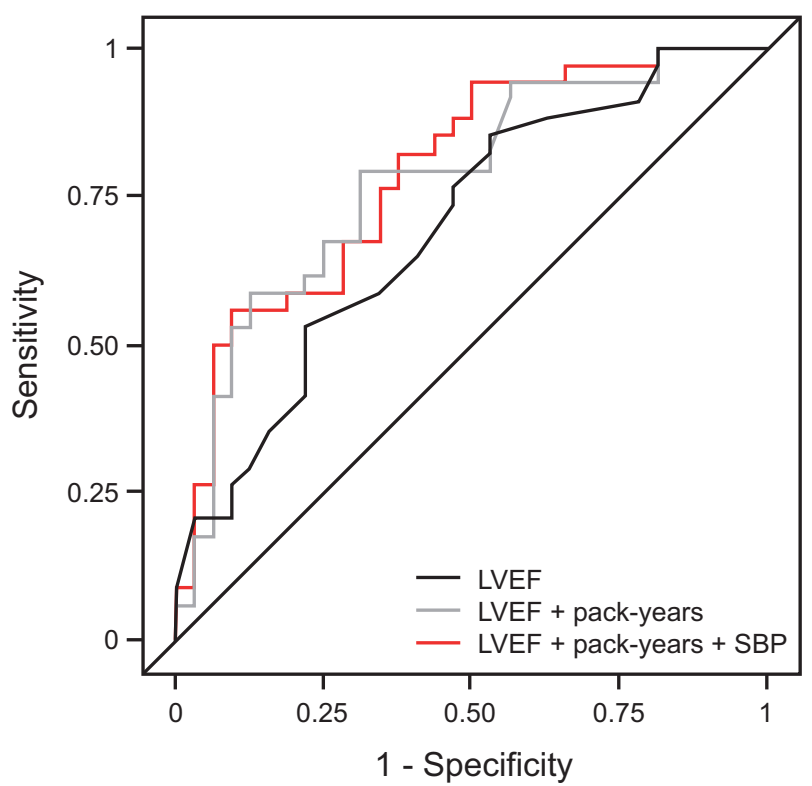

Fig. 1. Receiver operating characteristic curve analysis with left ventricular ejection fraction (LVEF), with LVEF plus pack-years and a model with the 3 predictors LVEF + pack-years + systolic blood pressure (SBP) for inspiratory muscle weakness discrimination.

in subjects with inspiratory muscle weakness and with no significant influence on the 6-min walk test distance. The lower limbs, such as the quadriceps and psoas muscles, ${ }^{28}$ have antigravitational postural activity, and they may be affected first during inactivity, rather than the upper limbs. ${ }^{29}$ In the upper limbs, we observed similar handgrip strength in the inspiratory muscle weakness and the no inspiratory muscle weakness groups, probably because our subjects had mild-to-moderate chronic heart failure (New York Heart Association functional class II and III), without a global myopathy. Reduced handgrip strength has been associated with increased frailty, morbidity, and mortality in subjects with advanced chronic heart failure. ${ }^{30}$

Chronic heart failure alone alters lung compliance and leads to the development of mild obstructive and restrictive alterations in lung function, while reducing gas exchange and increasing work of breathing (via reduce compliance), airway obstruction, and mechanical airway impedance. ${ }^{6,31-33}$ In fact, we observed no significant differences in ventilatory patterns between the inspiratory muscle weakness and the no inspiratory muscle weakness groups. Of 70 subjects, 28 (40\%) showed restrictive pulmonary alterations that was in line with other study that showed similar prevalence in subjects with chronic heart failure. ${ }^{34}$ The abnormal restrictive lung function is directly associated with heart failure severity because patients with cardiomegaly may have reduced total lung volume capacity. ${ }^{34}$

Based on our results and others, one could argue that smoking status could be a confounding variable for inspiratory muscle weakness because it is a major risk factor in the development of COPD and ischemic cardiomyopathy. ${ }^{29}$ In the current study, we examined the relationship that smoking status had to inspiratory muscle weakness and found that never smokers, ex-smokers, and current smokers had similar frequencies within the 2 groups. These results were in agreement with the systemic cytokine results, which were similar between the 2 groups. Although several biological processes are associated with smoking, including inflammation, early cellular apoptosis, extracellular matrix depletion, and oxidative stress, ${ }^{35}$ we found no significant difference in the systemic cytokines.

Chronic heart failure is also accompanied by an inflammatory response to the protein anabolic-catabolic imbalance, to protein degradation in the skeletal muscles, and to the tissue injury that occurs in the failing heart. Subjects with chronic heart failure usually have elevated levels of inflammatory cytokines, cell adhesion molecules, and chemokines, particularly in acute chronic heart failure exacerbations. For instance, high concentrations of tumor necrosis factor alpha and interleukin (IL) 6 in the circulation may contribute to a reduction in diaphragm contratility. ${ }^{36,37}$ However, circulating concentrations of tumor necrosis factor alpha and IL-6 lower than $100 \mathrm{pg} / \mathrm{mL}$ may not be sufficient to elicit respiratory muscle dysfunction. ${ }^{36}$ In addition, tumor necrosis factor alpha inhibitors failed to improve clinical status or outcomes, such as hospitalization and death, in subjects with chronic heart failure. ${ }^{38}$

In the present study, although the subjects with inspiratory muscle weakness showed trends toward higher concentrations of some cardiovascular and inflammatory biomarkers, for instance, growth differentiation factor-15 $(P=.64)$, serum neutrophil gelatinase-associated lipocalin $(P=.29)$, soluble vascular cell adhesion molecule-1 $(P=.17)$, IL-4 $(P=.14)$, IL-8 $(P=.40)$, and IL-10 $(P=.17)$, no significant differences were found between the inspiratory muscle weakness and the no inspiratory muscle weakness groups, possibly explained by greater interindividual clinical variations associated with the number of subjects in each group as well as the similar proportion of subjects who were never smokers, ex-smokers, and current smokers in the two groups. Indeed, we found that pack-years smoked was significantly greater in the inspiratory muscle weakness group and was a key predic- 
tor of inspiratory muscle weakness. Analysis of these findings indicates that pack-years smoked represents a better measure of possible damage and disease imposed from smoking compared with smoking status alone.

We found pulmonary hypertension in $46 \%$ of the subjects with chronic heart failure in our study, similar to previous descriptions of 26 to $80 \% .39$ Pulmonary hypertension can contribute to respiratory muscle weakness by increasing dead space and impairing alveolar gas exchange, which results in inefficient ventilation. ${ }^{40,41}$ In the present study, the proportion of subjects with pulmonary hypertension was significantly greater in the inspiratory muscle weakness group, with 2 subjects with pulmonary hypertension in the inspiratory muscle weakness group for every 1 subject with pulmonary hypertension in the no inspiratory muscle weakness group.

Furthermore, we found an inverse correlation between inspiratory muscle strength and pulmonary hypertension; however, pulmonary hypertension was not relevant in the multivariate model that predicts inspiratory muscle weakness. The subjects with pulmonary hypertension have been found to have marked inspiratory muscle weakness that seems to be just as amenable to inspiratory muscle training, as in subjects with systolic chronic heart failure. ${ }^{41}$ Robust data have demonstrated the important role that inspiratory muscle training has in improving many of the pathophysiologic manifestations associated with chronic heart failure, including peak oxygen consumption, ventilatory efficiency, 6-min walk distance, and even pulmonary artery pressure. ${ }^{42}$ Thus, subjects suspected to have inspiratory muscle weakness based on pack-years smoked, LVEF, and SBP should be examined for inspiratory muscle weakness and be provided inspiratory muscle training if inspiratory muscle weakness exists. Reducing inspiratory muscle weakness has the potential to improve many of the deleterious effects of chronic heart failure.

Our study had limitations. We did not measure the peak or the maximum oxygen consumption, which is an accepted standard for testing cardiopulmonary capacity assessment in chronic heart failure. However, we used other clinically meaningful functional capacity tests, including $\mathrm{P}_{\text {Imax }}$ and $\mathrm{P}_{\mathrm{Emax}}$, peripheral skeletal muscle strength, a submaximum exercise capacity and functional performance measure (6-min walk test), and lung function. Studies report that maximum respiratory pressures significantly correlate with peak oxygen consumption in subjects with chronic heart failure. ${ }^{43,44}$ The 6-min walk test can also determine the maximum exercise capacity in patients with debilitated chronic heart failure. ${ }^{45}$ Also, we did not measure respiratory muscle endurance.

Muscle function is characterized by strength and endurance, and the loss of either one can result in muscle weakness and impaired performance. However, there is evidence that the degree of dyspnea in subjects with chronic heart failure is not correlated with respiratory muscle fatigability but rather with muscle strength. ${ }^{46}$ An additional concern is that the optimum cutoff point for $\mathrm{P}_{\text {Imax }}$ used to determine inspiratory muscle weakness would be lower in subjects administered $\beta$-blockers ${ }^{47}$ and higher in subjects administered angiotensin-converting enzyme inhibitors because these agents seem to preserve actin myosin crossbridge properties of the diaphragm. ${ }^{48}$ However, there were no significant differences in the use of $\beta$-blockers (variation between $97 \%$ and $100 \%$ ) and angiotensin-converting enzyme inhibitors (variation between 59\% and 61\%) between the 2 groups of subjects.

\section{Conclusions}

Among a variety of demographic, clinical, functional capacity, and inflammatory and/or cardiovascular diseases biomarkers, we determined a clinical model with simple, noninvasive, and easy-to-obtain variables (LVEF, SBP, and pack-years) that combined predicted inspiratory muscle weakness in subjects with chronic heart failure, New York Heart Association functional class II and III. These results provided important findings to assist in the clinical decision making and management of patients with chronic heart failure. Inspiratory muscle training may represent a key strategy in the treatment of patients with chronic systolic chronic heart failure when inspiratory muscle weakness exists.

\section{ACKNOWLEDGMENTS}

We thank Dr Carmen Diva Saldiva de André and Dr José Juquemura for helping us with statistics.

\section{REFERENCES}

1. Miyagi M, Kinugasa Y, Sota T, Yamada K, Ishisugi T, Hirai M, et al. Diaphragm muscle dysfunction in patients with heart failure. J Card Fail 2018;24(4):209-216.

2. Mancini DM, Henson D, LaManca J, Levine S. Evidence of reduced respiratory muscle endurance in patients with heart-failure. J Am Coll Cardiol 1994;24(4):972-981.

3. Gomes-Neto M, Ferrari F, Helal L, Lopes AA, Carvalho VO, Stein $\mathrm{R}$. The impact of high-intensity inspiratory muscle training on exercise capacity and inspiratory muscle strength in heart failure with reduced ejection fraction: a systematic review and meta-analysis. Clin Rehabil 2018;32(11):1482-1492.

4. Dall'Ago P, Chiappa GR, Guths H, Stein R, Ribeiro JP. Inspiratory muscle training in patients with heart failure and inspiratory muscle weakness. J Am Coll Cardiol 2006;47(4):757-763.

5. Verissimo P, Casalaspo TJ, Gonçalves LH, Yang AS, Eid RC, Timenetsky KT. High prevalence of respiratory muscle weakness in hospitalized acute heart failure elderly patients. PLoS One 2015;10(2): $\mathrm{e} 0118218$.

6. Meyer FJ, Borst MM, Zugck C, Kirschke A, Schellberg D, Kübler W, Haass M. Respiratory muscle dysfunction in congestive heart failure: clinical correlation and prognostic significance. Circulation 2001;103(17):2153-2158. 
7. van Hees HW, van der Heijden HF, Ottenheijm CA, Heunks LM, Pigmans CJ, Verheugt FW, et al. Diaphragm single-fiber weakness and loss of myosin in congestive heart failure rats. Am J Physiol Heart Circ Physiol 2007;293(1):H819-H828.

8. Coirault C, Guellich A, Barbry T, Samuel JL, Riou B, Lecarpentier Y. Oxidative stress of myosin contributes to skeletal muscle dysfunction in rats with chronic heart failure. Am J Physiol Heart Circ Physiol 2007;292(2):H1009-H1017.

9. Kawauchi TS, Umeda IIK, Braga LM, Mansur AP, Rossi-Neto JM, Guerra de Moraes Rego Sousa A, et al. Is there any benefit using low-intensity inspiratory and peripheral muscle training in heart failure? A randomized clinical trial. Clin Res Cardiol 2017;106(9):676685.

10. Kawauchi TS, Umeda IIK, Braga LM, Mansur AP, Rossi-Neto JM, Guerra de Moraes Rego Sousa A, et al. Erratum to: Is there any benefit using low-intensity inspiratory and peripheral muscle training in heart failure? A randomized clinical trial. Clin Res Cardiol 2017;106(9):764-765.

11. Craig CL, Marshall AL, Sjöström M, Bauman AE, Booth ML, Ainsworth BE, et al. International Physical Activity Questionnaire: 12country reliability and validity. Med Sci Sports Exerc 2003;35(8): 1381-1395.

12. Ciconelli RM, Ferraz MB, Santos W, Meinão I, Quaresma MR. Brazilian-Portuguese version of the SF-36. A reliable and valid quality of life outcome measure. Rev Bras Reumatol 1999;39(3):143150.

13. Carvalho VO, Guimarães GV, Carrara D, Bacal F, Bocchi FA. Validação da Versão em Português do Minnesota Living with Heart Failure Questionnaire. Arq Bras Cardiol 2009;93(1):39-44.

14. American Thoracic Society/European Respiratory Society. ATS/ERS statement on respiratory muscle testing. Am J Respir Crit Care Med 2002;166(4):518-624.

15. Neder JA, Andreoni S, Lerario MC, Nery LE. Reference values for lung function tests. II. Maximal respiratory pressures and voluntary ventilation. Braz J Med Biol Res 1999;32(6):719-727.

16. Standardization of spirometry, 1994 Update. American Thoracic Society. Am J Respir Crit Care Med 1995;152(3):1107-1136.

17. Global Initiative for Chronic Obstructive Lung Disease. Bethesda: Global Initiative for Chronic Obstructive Lung Disease; GOLD Spirometry Guide; 2010. https://goldcopd.org/wp-content/uploads/2016/ 04/GOLD_Spirometry_2010.pdf. Accessed August 12, 2019.

18. ATS Committee on Proficiency Standards for Clinical Pulmonary Function Laboratories. ATS statement: guidelines for the six-minute walk test. Am J Respir Crit Care Med 2002;166(1):111-117.

19. Pavlou M, Ambler G, Seaman SR, Guttmann O, Elliott P, King M, Omar RZ. How to develop a more accurate risk prediction model when there are few events. BMJ 2015;351:h3868.

20. Ribeiro JP, Chiappa GR, Neder JA, Frankenstein L. Respiratory muscle function and exercise intolerance in heart failure function. Curr Heart Fail Rep 2009;6(2):95-101.

21. Wong E, Selig S, Hare DL. Respiratory muscle dysfunction and training in chronic heart failure. Heart Lung Circ 2011;20(5):289294.

22. Gosker HR, Wouters EF, van der Vusse GJ, Schols AM. Skeletal muscle dysfunction in chronic obstructive pulmonary disease and chronic heart failure: underlying mechanisms and therapy perspectives. Am J Clin Nutr 2000;71(5):1033-1047.

23. Hammond MD, Bauer KA, Sharp JT, Rocha RD. Respiratory muscle strength in congestive heart failure. Chest 1990;98(5):1091-1094.

24. Nishimura Y, Maeda H, Tanaka K, Nakamura H, Hashimoto Y, Yokoyama M. Respiratory muscle strength and hemodynamics in chronic heart failure. Chest 1994;105(2):355-359.

25. Moreno AM, Castro RR, Silva BM, Villacorta H, Sant'Anna Junior $\mathrm{M}$, Nóbrega AC. Intercostal and forearm muscle deoxygenation dur- ing respiratory fatigue in patients with heart failure: potential role of a respiratory muscle metaboreflex. Braz J Med Biomed Res 2014; 47(11):972-976.

26. Mainguy V, Maltais F, Saey D, Gagnon P, Martel S, Simon M, Provencher S. Peripheral muscle dysfunction in idiopathic pulmonary arterial hypertension. Thorax 2010;65(2):113-117.

27. Saey D, Michaud A, Couillard A, Côté CH, Mador MJ, LeBlanc P, et al. Contractile fatigue, muscle morphometry, and blood lactate in chronic obstructive pulmonary disease. Am J Respir Crit Care Med 2005;171(10):1109-1015.

28. Lopez PD, Nepal P, Akinlonu A, Nekkalapudi D, Kim K, Cativo EH, et al. Low skeletal muscle mass independently predicts mortality in patients with chronic heart failure after an acute hospitalization. Cardiology 2019;142(1):28-36.

29. Tanner RE, Brunker LB, Agergaard J, Barrows KM, Briggs RA, Kwon OS, et al. Age-related differences in lean mass, protein synthesis and skeletal muscle markers of proteolysis after bed rest and exercise rehabilitation. J Physiol 2015;593(18):4259-4273.

30. Chung CJ, Wu C, Jones M, Kato TS, Dam TT, Givens RC, et al. Reduced handgrip strength as a marker of frailty predicts clinical outcomes in patients with heart failure undergoing ventricular assist device placement. J Card Fail 2014;20(5):310-315.

31. Johnson BD, Beck KC, Olson LJ, O’Malley KA, Allison TG, Squires RW, Gau GT. Pulmonary function in patients with reduced left ventricular function: influence of smoking and cardiac surgery. Chest 2001;120(6):1869-1876.

32. Meyer FJ, Zugck C, Haass M, Otterspoor L, Strasser RH, Kübler W, Borst MM. Inefficient ventilation and reduced respiratory muscle capacity in congestive heart failure. Basic Res Cardiol 2000;95(4): 333-342.

33. Puri S, Baker BL, Oakley CM, Hughes JM, Cleland JG. Increased alveolar/capillary membrane resistance to gas transfer in patients with chronic heart failure. Brit Heart J 1994;72(2):140-144.

34. Olson TP, Beck KC, Johnson BD. Pulmonary function changes associated with cardiomegaly in chronic heart failure. J Card Fail 2007;13(2):100-107.

35. Yoshida T, Tuder RM. Pathobiology of cigarette smoke-induced chronic obstructive disease. Physiol Rev 2007;87(3):1047-1082.

36. Hartupee J, Mann DL. Position of inflammatory biomarkers in the heart failure landscape. J Cardiovasc Transl Res 2013;6(4):485492.

37. Janssen SP, Gayan-Ramirez G, Van den Bergh A, Herijgers P, Maes K, Verbeken E, Decramer M. Interleukin- 6 causes myocardial failure and skeletal muscle atrophy in rats. Circulation 2005;111(8):9961005.

38. Mann DL, McMurray JJ, Packer M, Swedberg K, Borer JS, Colucci WS, et al. Targeted anticytokine therapy in patients with chronic heart failure: results of the randomized etanercept worldwide evaluation (RENEWAL). Circulation 2004;109(13):15941602.

39. Ghio S, Gavazzi A, Campana C, Inserra C, Klersy C, Sebastiani $\mathrm{R}$, et al. Independent and additive prognostic value of right ventricular systolic function and pulmonary artery pressure in patients with chronic heart failure. J Am Coll Cardiol 2001;37(1): 183-188.

40. Meyer FJ, Lossnitzer D, Kristen AV, Schoene AM, Kübler W, Katus HA, Borst MM. Respiratory muscle dysfunction in idiopathic pulmonary arterial hypertension. Eur Respir J 2005;25(1): 125-130.

41. Filusch A, Ewert R, Altesellmeier M, Zugck C, Hetzer R, Borst MM, et al. Respiratory muscle dysfunction in congestive heart failure The role of pulmonary hypertension. Int J Cardiol 2011;150(2): 182-185. 
42. Cahalin LP, Arena RA. Breathing exercises and inspiratory muscle training in heart failure. Heart Fail Clin 2015;11(1):149-172.

43. Nanas S, Nanas J, Kassiotis C, Alexopoulos G, Samakovli A, Kanakakis $\mathrm{J}$, et al. Respiratory muscles performance is related to oxygen kinetics during maximal exercise and early recovery in patients with congestive heart failure. Circulation 1999;100(5):503-508.

44. Chua TP, Anker SD, Harrington D, Coats AJ. Inspiratory muscle strength is a determinant of maximum oxygen consumption in chronic heart failure. Br Heart J 1995;74(4):381-385.

45. Cahalin LP, Arena R, Guazzi M. Comparison of heart rate recovery after the six-minute walk test to cardiopulmonary exercise testing in patients with heart failure and reduced and preserved ejection fraction. Am J Cardiol 2012;110(3):467-468.
46. Mancini DM, Henson D, LaManca J, Levine S. Respiratory muscle function and dyspnea in patients with chronic congestive heart failure. Circulation 1992;86(3):909-918.

47. Frankenstein L, Nelles M, Meyer FJ, Sigg C, Schellberg D, Remppis BA, et al. Validity, prognostic value and optimal cutoff of respiratory muscle strength in patients with chronic heart failure changes with beta-blocker treatment. Eur J Cardiovasc Prev Rehabil 2009;16(4): 424-429.

48. Lecarpentier Y, Coirault C, Lerebours G, Desche P, Scalbert E, Lambert F, Chemla D. Effects of angiotensin-converting enzyme inhibition on crossbridge properties of diaphragm in cardiomyopathic hamsters of the dilated bio 53-58 strain. Am J Respir Crit Care Med 1997;155(2):630-636. 